Research Article

\title{
The Study of Key Stratum Location and Characteristics on the Mining of Extremely Thick Coal Seam under Goaf
}

\author{
Gaochuan Guo ${ }^{1,2}$ and Yongkang Yang $\mathbb{D}^{3}$ \\ ${ }^{1}$ School of Energy Science and Engineering, Henan Polytechnic University, Jiaozuo, Henan 454000, China \\ ${ }^{2}$ Taiyuan Design and Research Institute Group Co., Ltd. of Coal Industry, Taiyuan, Shanxi 030001, China \\ ${ }^{3}$ Key Laboratory of In-situ Property-improving Mining of Ministry of Education, Taiyuan University of Technology, Taiyuan, \\ Shanxi 030024, China \\ Correspondence should be addressed to Yongkang Yang; yongkang8396@163.com
}

Received 28 June 2020; Revised 11 January 2021; Accepted 17 January 2021; Published 11 February 2021

Academic Editor: Fengqiang Gong

Copyright (C) 2021 Gaochuan Guo and Yongkang Yang. This is an open access article distributed under the Creative Commons Attribution License, which permits unrestricted use, distribution, and reproduction in any medium, provided the original work is properly cited.

\begin{abstract}
The basis of traditional ground pressure and strata control techniques is the key strata theory, wherein the position of the key stratum can easily be determined for coal seams with regular thickness and without goaf. However, in the case of mining ultrathick coal seams underneath goaf, the traditional methods used for the calculation of key stratum position need to be improved in order to account for the additional coal seam thickness and the presence of an upper goaf. This study analyzed the failure height and collapse characteristics of overlying strata during excavation for determining the structure of the failed overlying strata. The results indicate that the intercalation and overlying strata gradually evolve into a large "arch structure" and a small "arch structure" during longwall mining, respectively. A mechanical model of the bearing characteristics of the interlayer key strata structure was established according to the structure of the intercalation rock layer, which is a hinged block structure. The results of the model indicate that the maximum principal stress occurs when the key strata portion of the arch structure bears the overlying load. Consequently, the movement and position of the interlayer key strata can be evaluated throughout the mining process of the ultrathick coal seams underneath goaf. This method was used to determine the position of interlayer key stratum of overlying strata in Xiegou coal mine. And the results agree with that of the engineering practice. The results are significant to determine the key strata position during ultrathick coal seam underneath goaf longwall mining.
\end{abstract}

\section{Introduction}

Rock masses are in equilibrium stress states prior to excavation operations [1-3]; afterwards, the redistribution of internal stress occurs until a new equilibrium is attained as a result of the above disruption to the stress states of the rock masses [4-7]. Throughout the excavation process, the overlying strata undergo varying degrees of deformation, movement, and destruction that can significantly impact the safety and efficiency of the mining operation [8-11]. In terms of coal mining operations, the deformation and damage will present as a variety of phenomenon that includes gas gushing, water inrush, rock burst, surface subsidence, and numerous other mine pressure-induced disasters [12-23]. Researchers have thoroughly studied the mining-induced disasters and have put forward numerous theories, such as pressure arch, cantilever beam, hinged rock block, and transfer rock beam. Qian et al. [16-18] developed the key stratum theory, which provides a theoretical basis for mine pressure appearance and overlying strata control as well as for the field of mine pressure control [13]. In the key stratum theory, the failure of a key stratum, which is defined as the stratum that controls the movement of the whole or a portion of the overlying strata, will cause the simultaneous subsidence of a portion or the entire overlying strata. Wang et al. [24] utilized the key stratum theory to analyze the fracture failure of the overlying hard sandstone layer during the mining of a medium thick coal seam in the Tashan coal 
mine. Hu et al. [25] used the key strata theory and corresponding prediction of key strata movement to make improvements upon coal and coalbed methane coextraction techniques and technologies. Du and Gao [26] suggest that, for mines with similar stratigraphic conditions, changes in key strata bulking factor and structural stability were the dominant factors that influenced the height of the fractured water-conducting zones for varying methods of mining. $\mathrm{Xu}$ et al. $[27,28]$ utilized the key strata theory to predict surface subsidence and subsidence of overlying strata. Li et al. [29] studied the spatial relationships between key strata requirements for strata fracturing and their influence on the height of conductive fracture zones. He et al. [30] studied the influence of key strata on the shape of strata movement boundary.

The majority of high-yield Chinese coal mines have thick coal seams, as the movement of overlying strata throughout mining in such mines has been a focus of research and has been thoroughly and extensively studied. Ju and $\mathrm{Xu}$ [31] studied the structural characteristics of key strata and the behavior of a fully mechanized longwall face with $7.0 \mathrm{~m}$ height chocks; furthermore, the behavior of both support systems and overlying strata was analyzed during sublevel caving of a thick coal seam [32]. Ma et al. [33] studied the deformation characteristics of and established mechanical model for overlying stratum deformation during backfilling with fully mechanized and retaining roadways along the gob area. The mining of thick coal seams under goaf is very complicated. However, some problems in the mining of thick coal seam under goaf are very complicated. When the distance between coal seam and goaf is between $30 \mathrm{~m}$ and $80 \mathrm{~m}$, there is no obvious safety problem in descending coal mining for common working face, but for the fault zone of coal seam with a thickness of $15 \mathrm{~m}$, the fault zone passes through the goaf directly. In goaf, the movement of main roof rupture can directly affect the surface of the Earth's surface due to the transfer of load in fractured rock mass; when coal pillar exists in goaf, harmful gas accumulation and waste water accumulation may occur, resulting in coal and gas outburst, spontaneous combustion of coal seam, and water inrush $[6,25]$; the stress concentration of residual coal pillar in goaf may suddenly lose stability or cause shock pressure $[9,24]$. The key to control the strata behavior is to understand the structural characteristics of key strata and its movement law [31]. There is little research on the position of the key layer in the mining of the very thick coal seam under the goaf, so it is difficult to explain the position of the key layer in the mining of the extrathick coal seam under the goaf. Because of the change in coal seam thickness and the load of overlying strata, the position of the key layer may deviate from the traditional calculation method. Therefore, determining the location of the critical layer is the key.

In this study, UDEC is used to study the failure height and collapse characteristics of overlying strata during ultrathick coal seam underneath goaf longwall mining. A mechanical model of the interlayer key stratum structure is established, and the movement periods of the key strata in the thick coal seam underneath goaf are determined. The position of interlayer key stratum during thick coal seam under goaf mining is also evaluated. This method is applied to the Xiegou coal mine, and the position of interlayer key stratum of overlying strata is determined by programming calculation.

\section{Numerical Study on the Collapse Characteristics of Overlying Strata during Ultrathick Coal Seam Longwall Mining underneath Goaf}

2.1. Model Setup. A numerical model was created using UDEC, with model dimensions of $240 \times 180 \mathrm{~m}^{2}$ and a $20 \mathrm{~m}$ wide remnant coal pillar in the upper $8^{\text {th }}$ coal seam goaf, as shown in Figure 1. Horizontal and vertical displacements were constrained at the bottom of the model, and horizontal displacement was constrained at the left- and right-side boundaries of the numerical model. And a stress boundary was applied at the upper boundary. The model with interlayer rock thicknesses of total $35 \mathrm{~m}$ was established. The mechanical parameters of coal, rock, and coal-rock contact surfaces are listed in Table 1.

2.2. Results of Numerical Simulations. The failure height and collapse characteristics of a $35 \mathrm{~m}$ thick interlayer rock were numerically determined by using UDEC. The simulation indicates that damage to overlying layers increases as the working face advances. When the working face advances $40 \mathrm{~m}$, the lower immediate roof falls behind the working face, the upper roof is directly broken, and the damage height reaches $25 \mathrm{~m}$, forming a small "arch structure," as shown in Figure 2(a). When the working face advances $60 \mathrm{~m}$, the upper immediate roof collapses and the damage height reaches $35 \mathrm{~m}$, which means that the damage has reached the lower boundary of the goaf, and the small "arch structure" evolves into a large "arch structure," as shown in Figure 2(b). When the working face advances $80 \mathrm{~m}$, the lower main roof becomes degraded and the damage height reaches $70 \mathrm{~m}$, which indicates that the damage will penetrate into the upper goaf and will consequently cause the formation of a large mining induced fracture in front of the working face, as shown in Figure 2(c). When the working face advances $100 \mathrm{~m}$, the working face passes underneath the remnant coal pillar, the lower main roof collapses, the upper main roof breaks, and the damage height reaches $120 \mathrm{~m}$, as shown in Figure 2(d). When the working face advances $140 \mathrm{~m}$, it enters the goaf because the coal pillar in the middle of the upper coal seam directly affects the top suspension and does not linger. The damage height reaches the upper boundary of the model, and the hydraulic support is in the "given deformation" state, i.e., the separation of the immediate roof and the main roof occurred, and the support only bears all the weight of the rock strata collapsed by the immediate roof (Figure 2(e)); when the working face advances $180 \mathrm{~m}$, the overburden is completely collapsed, the overlaying strata form a large "arch structure," and the hydraulic support is in a "given load" state; that is, the load and deformation of the support depend on the interaction of the lower rock block in the regular 


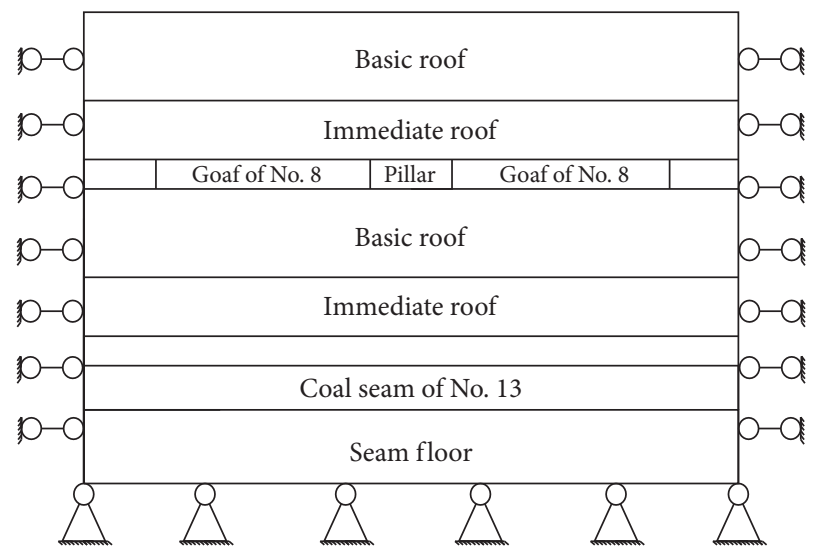

Figure 1: Initial design model figure.

TABle 1: The mechanical parameters of rock masses.

\begin{tabular}{|c|c|c|c|c|c|c|}
\hline Lithology & $\begin{array}{l}\text { Density } \\
\left(\mathrm{kg} \cdot \mathrm{m}^{3}\right)\end{array}$ & $\begin{array}{l}\text { Bulk modulus } \\
(\mathrm{GPa})\end{array}$ & $\begin{array}{l}\text { Shear elasticity } \\
(\mathrm{GPa})\end{array}$ & $\begin{array}{c}\text { Cohesion } \\
(\mathrm{MPa})\end{array}$ & $\begin{array}{c}\text { Internal friction } \\
\text { angle }\left({ }^{\circ}\right)\end{array}$ & $\begin{array}{c}\text { Strength of extension } \\
(\mathrm{MPa})\end{array}$ \\
\hline Packsand & 2600 & 27.1 & 7.0 & 27.1 & 27.0 & 3.2 \\
\hline $\begin{array}{l}\text { Medium-grained } \\
\text { sandstone }\end{array}$ & 2300 & 26.7 & 7.0 & 27.1 & 27.0 & 3.2 \\
\hline $\begin{array}{l}\text { Argillaceous } \\
\text { sandstone }\end{array}$ & 1800 & 26.7 & 6.0 & 26.2 & 25.2 & 1.2 \\
\hline No. 8 coal seam & 1300 & 9.2 & 8.0 & 3.2 & 24.2 & 1.5 \\
\hline $\begin{array}{l}\text { Medium-grained } \\
\text { sandstone }\end{array}$ & 2350 & 26.7 & 7.0 & 27.1 & 27.0 & 3.2 \\
\hline $\begin{array}{l}\text { Argillaceous } \\
\text { sandstone }\end{array}$ & 1800 & 20.6 & 7.0 & 6.5 & 18.5 & 1.5 \\
\hline Mudstone & 1500 & 18.1 & 5.0 & 6.5 & 16.5 & 1.2 \\
\hline No. 13 coal seam & 1300 & 9.2 & 8.0 & 3.2 & 24.2 & 1.2 \\
\hline Sandstone & 2400 & 26.7 & 7.0 & 27.2 & 27.0 & 3.5 \\
\hline
\end{tabular}

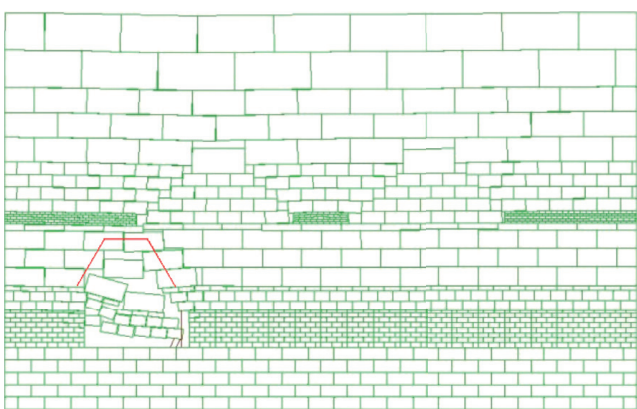

(a)

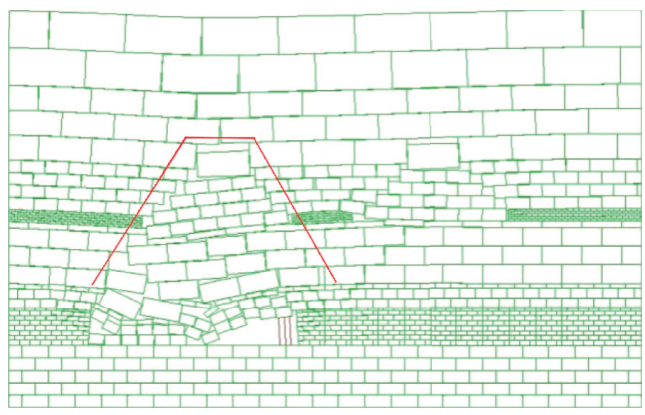

(c)

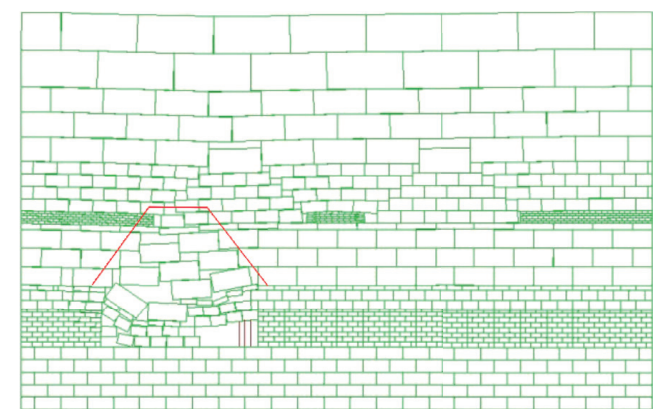

(b)

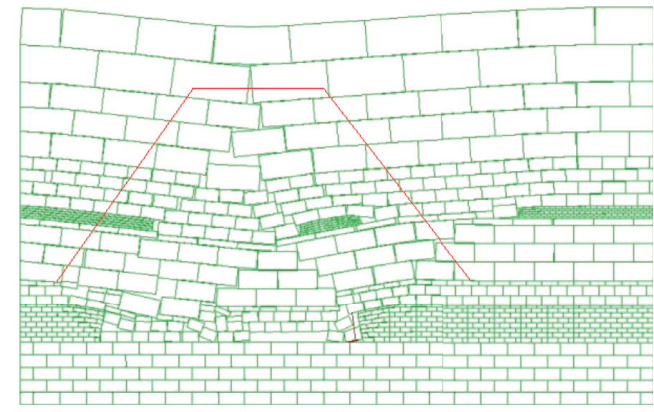

(d) 


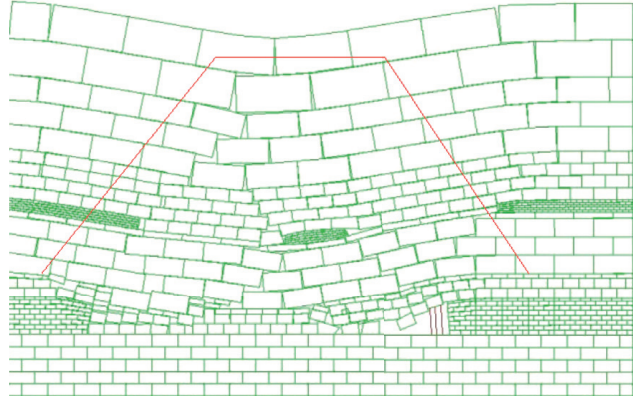

(e)

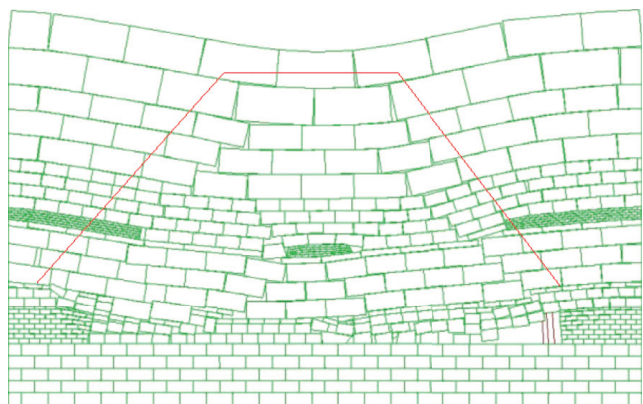

(f)

FIgURE 2: The evolution diagram of collapsing characteristics of overburden rock in $35 \mathrm{~m}$ interlayer: (a) advance of the working face $40 \mathrm{~m}$; (b) advance of the working face $60 \mathrm{~m}$; (c) advance of the working face $80 \mathrm{~m}$; (d) advance of the working face $100 \mathrm{~m}$; (e) advance of the working face $140 \mathrm{~m}$; (f) advance of the working face $180 \mathrm{~m}$.

moving zone, which will increase with the subsidence of the rock block until the rock block is balanced by the support of the fallen rock (Figure 2(f)). When the interlayer rock thickness is $35 \mathrm{~m}$, it can be observed that the interlayer rock layer and the overlying strata gradually evolve from a small "arch structure" into a large "arch structure" as the working face advances, and the interlayer rock layer is an articulated block structure.

\section{Interlayer Key Stratum Judgment Criteria}

3.1. Structural Bearing Characteristics of Key Stratum between Layers. Throughout the working face advance, the key stratum will undergo bending deformation as the immediate roof collapses. In this process, key stratum structures I and II can be considered an elastic foundation beam, while immediate roof III can be considered an elastic foundation [34]. The profile of the working face along the advancing direction was selected for analysis, and a mechanical model of the key stratum was established, as shown in Figure 3.

Structure I can be regarded as a cantilever structure under action of $q$, and $x \in\left[0, L_{k}\right]$, and its deflection differential equation can be expressed as

$$
E I \frac{d^{2}}{\mathrm{~d} x^{2}} y_{1}(x)=M_{I(1)}-Q_{I(1)} x+\int_{0}^{x} q(x-t) \mathrm{d} t .
$$

The equation of key stratum deflection curve is as follows:

$$
\begin{aligned}
y_{1}(x)= & \frac{1}{24 E I}\left(q x^{2}-4 Q_{I(1)} x+12 M_{I(1)}\right) x^{2} \\
& +A x+B, \quad x \in\left[0, L_{k}\right],
\end{aligned}
$$

where $q$ is the top load of the key stratum, $\mathrm{kN} / \mathrm{m}^{2}$; Eis the modulus of elasticity of the key stratum, GPa; and $I$ is the section moment of inertia of the key stratum, $I=(1 / 12) b h^{3}, \mathrm{~m}^{4}$.

Structure III and a combination of structures I and II can be considered an elastic foundation and a semi-infinite elastic beam, respectively.
Forces acting on structure II include the overburden load qand the reaction force of structure III to structure II, where $x \in[-\infty, 0]$, and the deflection differential equation of II can be expressed as

$$
\frac{d^{4}}{\mathrm{~d} x^{4}} y_{2}(x)+4 \beta^{4} y_{2}(x)=\frac{q}{E I}
$$

To compute the homogeneous linear differential equation, its general solution was achieved:

$$
y_{2}(x)=e^{\beta x}(C \cos \beta x+D \sin \beta x)+\frac{q}{4 E I \beta^{4}},
$$

where $\beta$ is the differential parameter $\left(\beta=\sqrt[4]{k / 4 E I}, \mathrm{~m}^{-1}\right)$ and $k$ is the elastic foundation coefficient $\left(\mathrm{N} / \mathrm{m}^{3}\right)$.

The boundary conditions of the key strata are as follows:

$$
\left\{\begin{array}{l}
y_{1}(-\infty)=\frac{C}{q} \\
y_{1}^{\prime \prime}(-\infty)=0 \\
y_{1}(0)=y_{2}(0) \\
y_{1}^{\prime}(0)=y_{2}^{\prime}(0) \\
y_{1}^{\prime}(0)=y_{2}^{\prime}(0) \\
y_{1}^{\prime \prime}(0)=y_{2}^{\prime \prime}(0) \\
y_{3}^{\prime}\left(L_{k}\right)=0 \\
y_{2}^{\prime \prime}\left(L_{k}\right)=0
\end{array}\right.
$$

The undetermined coefficients $A, B, C, D, M_{1(1)}$, and $Q_{1(1)}$ in the equation of flexural line can be obtained by solving the above equation, and the results are as follows: 


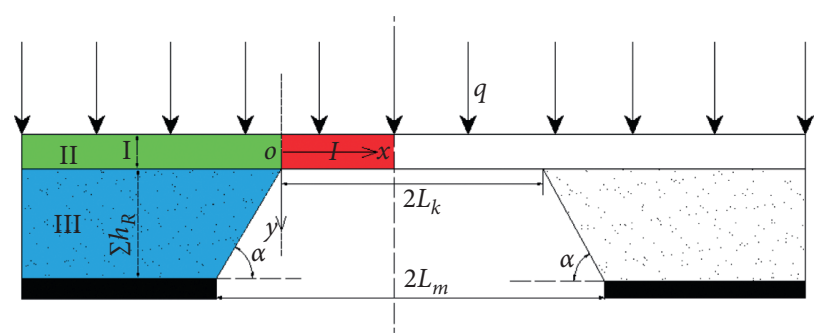

Figure 3: Mechanical model of key strata.

$$
\left\{\begin{array}{l}
A=-\frac{q L_{k}^{2}\left(2 \beta L_{k}+3\right)}{6 \beta E I\left(\beta L_{k}+1\right)} \\
B=\frac{q\left(2 \beta^{3} L_{k}^{3}+6 \beta^{2} L_{k}^{2}+6 \beta L_{k}+3\right)}{12 \beta^{4} E I\left(\beta L_{k}+1\right)} \\
C=\frac{q L_{k}\left(2 \beta^{2} L_{k}^{2}+6 \beta L_{k}+3\right)}{12 \beta^{3} E I\left(\beta L_{k}+1\right)} \\
D=\frac{q L_{k}\left(2 \beta^{2} L_{k}^{2}-3\right)}{12 \beta^{3} E I\left(\beta L_{k}+1\right)} \\
M_{1(1)}=\frac{q L_{k}\left(2 \beta^{2} L_{k}^{2}-3\right)}{6 \beta\left(\beta L_{k}+1\right)} \\
Q_{1(1)}=q L_{k} .
\end{array}\right.
$$

By substituting equation (6) into equations (2) and (4), respectively, the deflection analysis of the key strata and the bending moment analytical formula of the key strata can be obtained according to the differential analysis relationship between the key strata deflection and the bending moment.

According to equation (6), the normal stress, $\sigma_{x}$, on any section of the key strata is

$$
\sigma_{x}=\frac{M(x) y}{I_{Z}},
$$

where $I_{z}$ is the moment of inertia of the key strata $\left(I_{z}=(1 / 12) b h^{3}, \mathrm{~m}^{4}\right)$.

According to equation (7), the shear stress, $\tau_{x y}$, on any section of the key strata is

$$
\tau_{x y}=\frac{F_{s} S_{z}^{*}}{I_{z} b}=\frac{S_{z}^{*}}{I_{z} b} \frac{d M(x)}{d(x)},
$$

where $S_{z}^{*}$ is the static moment of the neutral axis of the area below the horizontal line of the I and II interfaces from the neutral axis and $S_{z}^{*}=(b / 2)\left(\left(h^{2} / 4\right)-y^{2}\right)$.

The expression of the maximum and minimum principal stresses of the unit body under normal stress, $\sigma$, and shear stress, $\tau$, is as follows:

$$
\left\{\begin{array}{l}
\sigma_{1}=\frac{\sigma_{x}+\sigma_{y}}{2}+\sqrt{\left(\frac{\sigma_{x}-\sigma_{y}}{2}\right)^{2}+\tau_{x y}^{2}} \\
\sigma_{2}=\frac{\sigma_{x}+\sigma_{y}}{2}-\sqrt{\left(\frac{\sigma_{x}-\sigma_{y}}{2}\right)^{2}+\tau_{x y}^{2}}
\end{array}\right.
$$

The maximum and minimum principal stress analytic equations for key strata bearing can be obtained by equation (9):

The immediate roof can be regarded as a wedge body, and the reaction force $q(x)$ transmitted from the key strata to the elastic foundation can be obtained according to the deflection analysis of the key strata. Let the polar coordinate system expression of the stress component of the point $M$ be obtained at any point $M(\varphi, \rho)$ in the immediate roof:

$$
\left\{\begin{array}{l}
\sigma_{\rho}=-q+\frac{\tan \alpha(1+\cos 2 \varphi)-(2 \varphi+\sin 2 \varphi)}{2(\tan \alpha-\alpha)} q \\
\sigma_{\varphi}=-q+\frac{\tan \alpha(1-\cos 2 \varphi)-(2 \varphi-\sin 2 \varphi)}{2(\tan \alpha-\alpha)} q \\
\tau_{\rho \varphi}=\tau_{\varphi \rho}=\frac{(1-\cos 2 \varphi)-\tan \alpha \sin 2 \varphi}{2(\tan \alpha-\alpha)} q .
\end{array}\right.
$$

Thus, the Cartesian coordinate system expression of the stress component of the point $M$ can be obtained as follows:

$$
\left\{\begin{array}{l}
\sigma_{x}=\frac{\sigma_{\rho}+\sigma_{\varphi}}{2}+\frac{\sigma_{\rho}-\sigma_{\varphi}}{2} \cos 2 \varphi-\tau_{\rho \varphi} \sin 2 \varphi \\
\sigma_{y}=\frac{\sigma_{\rho}+\sigma_{\varphi}}{2}-\frac{\sigma_{\rho}-\sigma_{\varphi}}{2} \cos 2 \varphi+\tau_{\rho \varphi} \sin 2 \varphi \\
\tau_{x y}=\tau_{y x}=\frac{\sigma_{\rho}-\sigma_{\varphi}}{2} \sin 2 \varphi+\tau_{\rho \varphi} \cos 2 \varphi
\end{array}\right.
$$

wherein 


$$
\left\{\begin{array}{l}
\sin 2 \varphi=\frac{2 x y}{x^{2}+y^{2}} \\
\cos 2 \varphi=\frac{x^{2}-y^{2}}{x^{2}+y^{2}} .
\end{array}\right.
$$

According to equations (10)-(12), the expressions of the stress components at any point in the immediate roof are obtained under the polar coordinate system or the Cartesian coordinate system, which can be substituted into equation (9) to find the equation for principal stress at any point.

The surrounding rock masses where the mining induced stress is greater than the in situ stress is defined as the stress arch. The results of the theoretical calculations indicate that the overlying load and the maximum principal stress contour will cause the formation of a stress arch in the key stratum, as shown in Figure 4. The stress arch is an arch structure in which the principal stresses in the key strata are coordinated and redistributed to form a control effect, but not objectively exist in the overlying strata.

\subsection{Periodic Weighting of Composite Key Strata and Main}

Roof. During the working face advance, the main roof will periodically sink and collapse after the first weighting. If the main roof does not collapse, it can be considered a cantilever beam and the period weighting interval of the key strata can be determined based on the maximum length of the noncollapsed cantilever as follows:

$$
L_{z}=h \sqrt{\frac{\sigma_{c}}{30 q}}
$$

where $h$ is the thickness of the main roof $(\mathrm{m}), \sigma_{c}$ is the compression strength of the supporting strata $(\mathrm{MPa})$, and $q$ is the load from other supporting strata $\left(\mathrm{kN} / \mathrm{m}^{2}\right)$.

Two or more key strata form a composite key stratum. If the distance between two key strata is less than a certain value, an effect similar to a composite beam is produced. The load bearing support capacity of these combined key strata will be significantly enhanced and will be much larger than the simple linear superposition value.

When the lithology and thickness of the No. 1 key strata $h_{1}$ are kept constant, only the thickness of the No. 2 key strata $h_{2}$ and the distance between the two key strata $\delta h$ are changed. At this time, the caving distance of the key strata No. 1 is also constantly changing. Therefore, the determining conditions for whether the key strata produce a composite effect are given by simulation:

$$
\begin{aligned}
& \frac{h_{2}}{h_{1}}=0.5+1.5 \frac{\delta h}{h_{1}}, \\
& \frac{\delta h}{h_{1}}=2.2,
\end{aligned}
$$

where $h$ is the thickness of the main roof $(\mathrm{m})$.

When satisfying the conditions of $\delta h / h_{1} \leq 2.2$ and $h_{2} / h_{1} \geq 0.5+1.5 \delta h / h_{1}$, a composite effect will occur between the two key stratus. If thickness ratio of the two key strata $h_{2} / h_{1}$ is kept constant, the composite effect will increase as $\delta h / h_{1}$ increases and the breaking distance of No. 1 key strata will increase.

When $\delta h / h_{1} \geq 2.2$, no composite effect exists between the key strata, and the composite effect is strongest when the interval is $1-3$ times. The results of the simulations indicate that the relationship between caving distance of No. 1 key strata and total caving distance without considering the composite effect is as follows:

$$
L_{m 1}=\frac{1}{n} \sum_{i=1}^{n}\left(L_{m}\right)=k_{1} L_{m}
$$

where $k_{1}$ is the amendable constant, it was determined by $\delta h / h_{1}$, and its value may be 1.15 .

\subsection{Composite Key Strata Position Judgment Method.} Fracture and deformation characteristics are the attributes that are used to identify the key strata, wherein the stratum that plays a decisive role in the determination of rock mass activity is termed the key stratum and the other strata are termed inferior key strata. Therefore, the failure and deformation of these two types of key strata will cause a portion or all of the movement of the overlying strata.

If there are $m$ overlying strata above the coal mining face, layer 1 and layer $n+1$ are set as hard rock, where $n<m$. The formation of the main key stratum of the layer $n+1$ must satisfy the deformation criterion (16) and the strength criterion (17).

The key stratum deformation criterion is

$$
\left.q_{a}(x)\right|_{n}=\frac{E_{a} h_{a}^{3} \sum_{i=1}^{n} \rho_{i} g h_{i}}{\sum_{i=1}^{n} E_{i} h_{i}^{3}},
$$

where $h_{a}$ is the thickness of layer No. $\alpha(\mathrm{m}), E_{a}$ is the elasticity modulus of layer No.a $(\mathrm{GPa}), \rho$ is the rock density $\left(\mathrm{kg} / \mathrm{m}^{3}\right)$, and $g$ is the gravitational acceleration $\left(\mathrm{m} / \mathrm{s}^{2}\right)$.

The key stratum strength criterion is

$$
\left.q_{a}(x)\right|_{n+1}<\left.q_{a}(x)\right|_{n}, \quad L_{n}<L_{n+1},
$$

where $L_{n}$ is the breaking distance of layer $n(\mathrm{~m})$ and $L_{n+1}$ is the breaking distance of layer $n+1(m)$.

If the calculation results do not satisfy equation (17), the gravity of all overburden strata supported by the hard rock strata $n+1$ should be applied to the hard rock strata $n$ as load. At this point, the breaking distance of the hard rock strata $k$ should be recalculated and the judgment should be made again.

\section{Field Application}

4.1. The Basic Conditions of 23103 Working Face in Xiegou Coal Mine. 23103 Fully mechanized caving working face is the first working face of No. 13 coal mining area No. 21, 


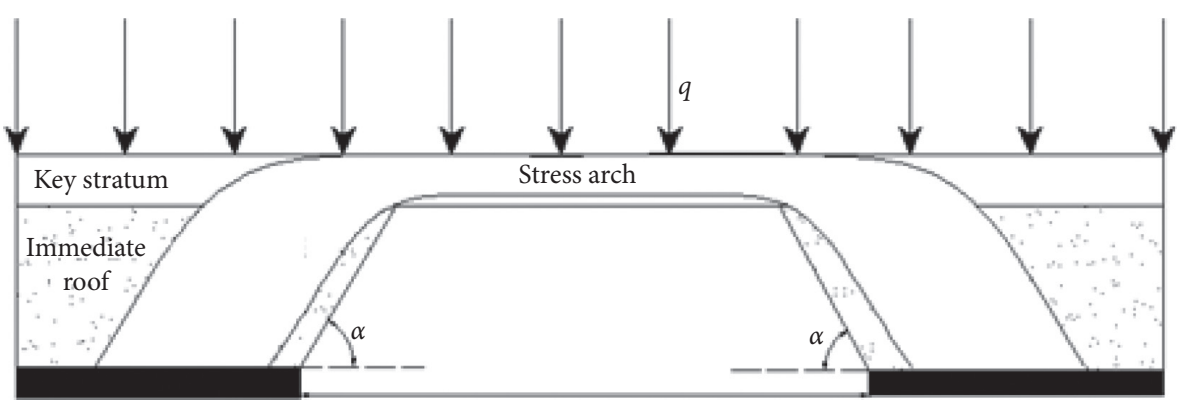

FIGURE 4: Sketch of major principal stress in key stratum.

which is located in the west of the 21-mining area. The mining strike of the working face is $2513 \mathrm{~m}$ long, the tilt length is $242.4 \mathrm{~m}$, the floor elevation of the working face is $698-758 \mathrm{~m}$, the ground elevation is $971-1140 \mathrm{~m}$, and the thickness of the overlying strata is $215-402 \mathrm{~m}$. According to the thickness of coal seam exposed by roadway driving and drilling is $14.00-15.92 \mathrm{~m}$ with an average of $15 \mathrm{~m}$, the industrial reserve of working face is $12.92 \mathrm{Mt}$ and recoverable reserve is $10.27 \mathrm{Mt}$. Considering with $5.0 \mathrm{Mt} / \mathrm{a}$, the service life of working face is $2.05 \mathrm{~A}$. The upper part of the working face is the goaf of No. 8 coal seam 18109 and 18107. The goaf scope and water volume are relatively clear. The overlying strata on the working face are shown in Table 2.

\subsection{Key Strata Position Prediction and Field Verification.} The key strata in the overburden strata shown in Table 2 are determined by programming calculation according to the deformation, support characteristics, and strength discrimination conditions of the above key strata. When \# 8 coal mine is being mined, \#6 coal is the main key strata, and $\# 14, \# 22$, and $\# 25$ are inferior key strata. After the mining of \# 8 coal, \#14,\#22, and \#25 inferior key strata all broke, and \#6 main key strata are deformed and separated. When \#13 coal is mined, \#6 is the main key strata, and \#30 and \#36 are inferior strata.

In practical field mining, it was found that shortly after the stoppage of No. 8 coal seam, a step crack appeared on the surface, as shown in Figure 5, indicating that the analysis of \#6 as the main key strata were reliable. In the mining process of 23103 working face of No. 13 coal seam, the peak load of support is always in highresistance operation state. The monitoring results of the supports showed that the main roof periodic pressure pace was at least $4.6 \mathrm{~m}$ and at most $38.4 \mathrm{~m}$, with an average of $15.12 \mathrm{~m}$. The average load curve of No. 77 support on 23103 working face is shown in Figure 6. When the top key strata are broken, the working resistance of the support will increase. In order to prevent the collapse of the support, blasting and pressure to release can be carried out in advance on the overly key strata.
TABLE 2: Rock formation columnar section of \#13 coal seam in Xiegou coal mine.

\begin{tabular}{|c|c|c|c|}
\hline No. & Name & Thickness (m) & Elasticity modulus (GPa) \\
\hline 1 & Loess & 26.84 & 0.25 \\
\hline 2 & Packsand & 7.95 & 4.03 \\
\hline 3 & Sandy mudstone & 12.18 & 5.44 \\
\hline 4 & Packsand & 8.50 & 13.25 \\
\hline 5 & Sandy mudstone & 20.30 & 10.63 \\
\hline 6 & $\begin{array}{l}\text { Medium } \\
\text { sandstone }\end{array}$ & 12.06 & 33.37 \\
\hline 7 & Sandy mudstone & 31.49 & 6.22 \\
\hline 8 & Packsand & 4.60 & 12.58 \\
\hline 9 & Sandy mudstone & 21.85 & 6.45 \\
\hline 10 & Mudstone & 25.22 & 3.61 \\
\hline 11 & Sandy mudstone & 3.60 & 9.75 \\
\hline 12 & $\begin{array}{l}\text { Medium } \\
\text { sandstone }\end{array}$ & 17.30 & 15.37 \\
\hline 13 & Sandy mudstone & 6.50 & 8.53 \\
\hline 14 & Packsand & 13.76 & 17.74 \\
\hline 15 & Mudstone & 6.56 & 5.47 \\
\hline 16 & Packsand & 3.82 & 8.36 \\
\hline 17 & Mudstone & 4.52 & 2.60 \\
\hline 18 & $\begin{array}{l}\text { Medium } \\
\text { sandstone }\end{array}$ & 7.84 & 12.79 \\
\hline 19 & Sandy mudstone & 4.12 & 7.53 \\
\hline 20 & Packsand & 7.02 & 6.43 \\
\hline 21 & Sandy mudstone & 9.51 & 9.59 \\
\hline 22 & $\begin{array}{l}\text { Medium } \\
\text { sandstone }\end{array}$ & 11.92 & 26.32 \\
\hline 23 & Mudstone & 15.02 & 4.51 \\
\hline 24 & \#6 coal mine & 1.50 & 0.99 \\
\hline 25 & Gritstone & 9.65 & 24.32 \\
\hline 26 & Siltstone & 3.71 & 9.10 \\
\hline 27 & Sandy mudstone & 1.00 & 8.57 \\
\hline 28 & \#8 coal mine & 5.69 & 2.15 \\
\hline 29 & Mudstone & 2.13 & 3.64 \\
\hline 30 & $\begin{array}{l}\text { Medium } \\
\text { sandstone }\end{array}$ & 8.31 & 28.45 \\
\hline 31 & Marlstone & 2.12 & 17.56 \\
\hline 32 & Mudstone & 2.01 & 6.52 \\
\hline 33 & \#9 coal mine & 0.51 & 0.55 \\
\hline 34 & Sandy mudstone & 2.43 & 10.29 \\
\hline 35 & Mudstone & 1.45 & 2.58 \\
\hline 36 & Gritstone & 5.39 & 19.57 \\
\hline 37 & Mudstone & 2.32 & 3.85 \\
\hline
\end{tabular}


TABle 2: Continued.

\begin{tabular}{|c|c|c|c|}
\hline No. & Name & Thickness (m) & Elasticity modulus (GPa) \\
\hline 38 & \#10 coal mine & 0.60 & 0.66 \\
\hline 39 & Mudstone & 2.26 & 4.68 \\
\hline 40 & Marlstone & 6.50 & 15.68 \\
\hline 41 & Sandy mudstone & 1.53 & 9.74 \\
\hline 42 & \#11 coal mine & 0.61 & 1.02 \\
\hline 43 & Mudstone & 1.76 & 2.85 \\
\hline 44 & Limestone & 2.56 & 6.37 \\
\hline 45 & Sandy mudstone & 2.08 & 10.24 \\
\hline 46 & Mudstone & 1.49 & 4.39 \\
\hline 47 & \#12 coal mine & 0.82 & 1.20 \\
\hline 48 & Mudstone & 1.00 & 3.80 \\
\hline 49 & $\begin{array}{l}\text { Medium } \\
\text { sandstone }\end{array}$ & 2.50 & 17.68 \\
\hline 50 & Micropsammite & 2.02 & 3.51 \\
\hline 51 & Mudstone & 2.07 & 2.67 \\
\hline 52 & Sandy mudstone & 1.50 & 10.85 \\
\hline 53 & \#13 coal mine & 5.25 & 1.36 \\
\hline 54 & Dirt band & 0.25 & 2.23 \\
\hline 55 & \#13 coal mine & 3.25 & 1.25 \\
\hline 56 & Dirt band & 0.25 & 2.64 \\
\hline 57 & \#13 coal mine & 4.15 & 1.48 \\
\hline 58 & Dirt band & 0.30 & 2.47 \\
\hline 59 & \#13 coal mine & 1.55 & 1.12 \\
\hline 60 & Mudstone & 2.00 & 3.62 \\
\hline 61 & \#14 coal mine & 0.33 & 0.85 \\
\hline 62 & Mudstone & 3.05 & 2.48 \\
\hline 63 & Sandy mudstone & 2.00 & 8.62 \\
\hline 64 & Limestone & 1.29 & 6.34 \\
\hline 65 & Mudstone & 1.00 & 4.58 \\
\hline 66 & \#15 coal mine & 0.44 & 0.63 \\
\hline 67 & Sandy mudstone & 3.00 & 7.25 \\
\hline 68 & Mudstone & 2.05 & 4.26 \\
\hline 69 & Siltstone & 2.56 & 13.48 \\
\hline 70 & Packsand & 2.41 & 7.68 \\
\hline
\end{tabular}

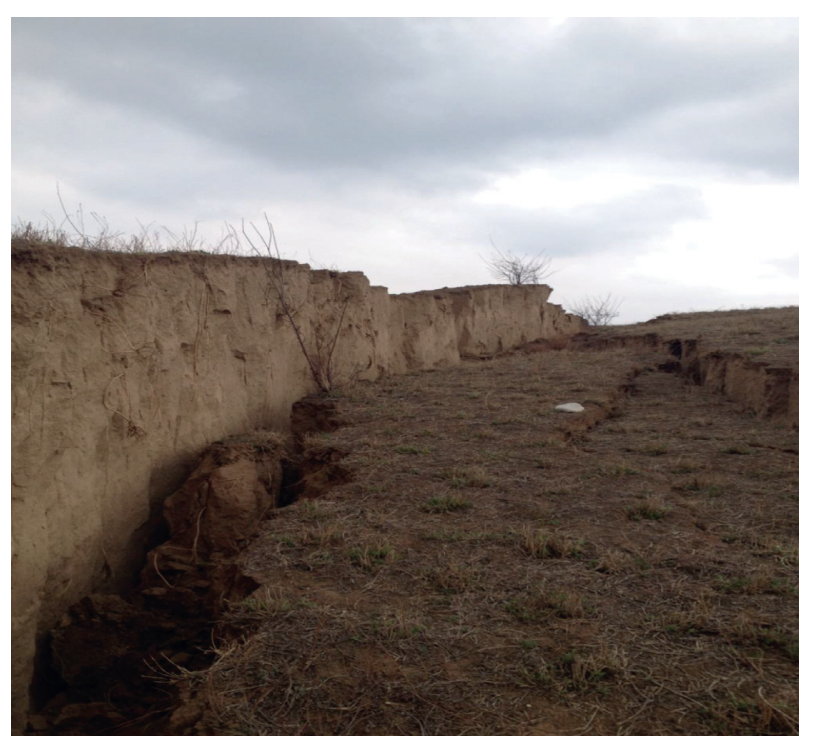

FIGURE 5: Surface stepped crack after the mining of No. 8 coal seam.

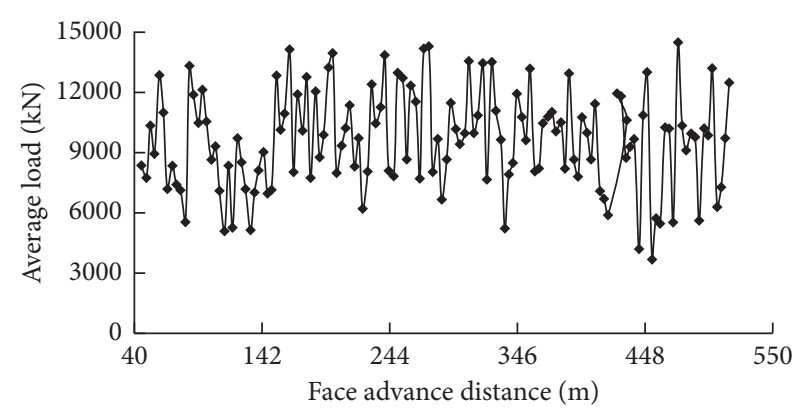

FIgURE 6: No. 77 support average load during 23103 working face advance.

\section{Conclusions}

(1) The failure height and collapse characteristics of overlying strata in thick coal seam mining underneath goaf are analyzed with UDEC software. When the interlayer rock thickness is $35 \mathrm{~m}$, it can be observed that the interlayer rock layer and the overlying strata gradually evolve from a small "arch structure" into a large "arch structure" as the working face advances, and the interlayer rock layer is an articulated block structure.

(2) Based on the mechanical model of the bearing characteristics of the interlayer key strata structure, it can be known that the maximum principal stress profile on the key layer section is the arch structure. The principal stresses of the key layers in this kind of arch structure coordinate with each other, redistribute and form a control effect, but they do not exist objectively in the overlying strata. Based on this, a method for evaluating the periodic weighting of the composite critical layer and the main roof is presented.

(3) A calculation method is presented to determine the position of the key strata based of the support, deformation characteristics, and strength of the key strata and applied this method to the determination of the position of the key strata over the Xiegou coal mine. And it has been verified by the field mining practice of 23103 working face in Xiegou coal mine.

\section{Data Availability}

The data used to support the findings of this study are included within the article.

\section{Conflicts of Interest}

The authors declare that there are no conflicts of interest regarding the publication of this paper.

\section{Acknowledgments}

This work was supported by the National Natural Science Foundation of China (Grant no. 51404167); Shanxi Scholarship Council of China (Grant no. HGKY2019038); Natural Science Foundation of Shanxi Province (Grant nos. 201801D121034 and 201901D211066); Shanxi Provincial Key 
R\&D Project (Grant no. 201803D31051); Shanxi Soft Science Research Project (Grant no. 2018041047-6); Shanxi Province Higher Education Reform and Innovation Project (J2019055); and China Postdoctoral Science Foundation Funding Project (Grant no. 2016M590151).

\section{References}

[1] P. R. Sheorey, "A theory for in Situ stresses in isotropic and transverseley isotropic rock," International Journal of Rock Mechanics and Mining Sciences \& Geomechanics Abstracts, vol. 31, no. 1, pp. 23-34, 1994.

[2] Q. Li, W. Fei, X. Liu, X. Wei, M. Jing, and X. Li, “Challenging combination of $\mathrm{CO}_{2}$ geological storage and coal mining in the Ordos basin, China," Greenhouse Gases: Science and Technology, vol. 4, no. 4, pp. 452-467, 2014.

[3] B. H. G. Brady and E. T. Brown, Rock Mechanics: For Underground Mining, Springer Science \& Business Media, Berlin, Germany, 2013.

[4] Q. Jiang, X.-t. Feng, J. Chen, K. Huang, and Y.-l. Jiang, "Estimating in-situ rock stress from spalling veins: a case study," Engineering Geology, vol. 152, no. 1, pp. 38-47, 2013.

[5] O. Stephansson, "Rock stress in the Fennoscandian shield," in Rock Testing and Site Characterizationpp. 445-459, Elsevier Science, Amsterdam, Netherlands, 1995.

[6] S. Yin, J. Zhang, and D. Liu, "A study of mine water inrushes by measurements of in situ stress and rock failures," Natural Hazards, vol. 79, no. 3, pp. 1961-1979, 2015.

[7] W. Qin and J. Xu, "Horizontal subzone characteristics and methane seepage properties of the gas flowing fracture zone above the gob," Advances in Civil Engineering, vol. 2018, Article ID 9071578, 12 pages, 2018.

[8] J.-L. Xie and J.-L. Xu, "Effect of key stratum on the mining abutment pressure of a coal seam," Geosciences Journal, vol. 21, no. 2, pp. 267-276, 2017.

[9] H. Yanli, Z. Jixiong, A. Baifu, and Z. Qiang, "Overlying strata movement law in fully mechanized coal mining and backfilling longwall face by similar physical simulation," Journal of Mining Science, vol. 47, no. 5, pp. 618-627, 2011.

[10] K. Wu, G.-L. Cheng, and D.-W. Zhou, "Experimental research on dynamic movement in strata overlying coal mines using similar material modeling," Arabian Journal of Geosciences, vol. 8, no. 9, pp. 6521-6534, 2015.

[11] S. Sang, H. Xu, L. Fang et al., "Stress relief coalbed methane drainage by surface vertical wells in China," International Journal of Coal Geology, vol. 82, no. 3-4, pp. 196-203, 2010.

[12] P. Xu, M. Zhang, Z. Lin et al., "Additional stress on a buried pipeline under the influence of coal mining subsidence," Advances in Civil Engineering, vol. 2018, Article ID 3245624, 16 pages, 2018.

[13] M. G. Qian, P. W. Shi, and J. L. Xv, Mining Pressure and Strata Control, China University of Mining and Technology Press, Xuzhou, China, 2010.

[14] H. Shi and F. X. Jiang, "Structural theories of overlying strata in longwall faces and their new development," Shandong Keji Daxue Xuebao/Journal of Shandong University of Science and Technology(Natural Science), vol. 24, no. 1, pp. 21-25, 2005.

[15] X. Lv, H. Zhou, A. Wang et al., "Characteristics of stress transfer and progressive fracture in overlying strata due to mining-induced disturbances," Advances in Civil Engineering, vol. 2018, Article ID 8967010, 13 pages, 2018.

[16] M. G. Qian, X. X. Miao, and J. L. Xu, "Key strata theory in strata control," Journal of China Coal Society, vol. 21, pp. 225-230, 1996.
[17] M. G. Qian, X. X. Miao, and J. L. Xu, "Theoretical study of keystratum in ground control," Journal of China Coal Society, vol. 21, no. 3, p. 225230, 1996.

[18] X. X. Miao, R. H. Chen, and H. Pu, "Analysis of breakage andcollapse of thick key strata around coal face," Chinese Journal of Rock Mechanics and Engineering, vol. 24, no. 8, pp. 1289-1295, 2005.

[19] C.-P. Lu, L.-M. Dou, N. Zhang et al., "Microseismic frequency-spectrum evolutionary rule of rockburst triggered by roof fall," International Journal of Rock Mechanics and Mining Sciences, vol. 64, pp. 6-16, 2013.

[20] J. Ju and J. Xu, "Surface stepped subsidence related to top-coal caving longwall mining of extremely thick coal seam under shallow cover," International Journal of Rock Mechanics and Mining Sciences, vol. 78, pp. 27-35, 2015.

[21] R. Krishna, "Measurement of sub-surface strata behavior in board and pillarmining: a case study," Mining Science and Technology, vol. 13, p. 33749, 1991.

[22] K. B. Singh and T. N. Singh, "Ground movements over longwall workings in theKamptee coalfield, India," Engineering Geology, vol. 50, p. 12539, 1998.

[23] P. R. Sheory, "Ground subsidence observations and a modified influence function method for complete subsidence prediction," International Journal of Rock Mechanics and Mining Sciences, vol. 37, p. 80118, 2000.

[24] W. Wang, Y.-p. Cheng, H.-f. Wang et al., "Fracture failure analysis of hard-thick sandstone roof and its controlling effect on gas emission in underground ultra-thick coal extraction," Engineering Failure Analysis, vol. 54, pp. 150-162, 2015.

[25] G. Hu, J. Xu, F. Zhang, C. Zhao, W. Qin, and Y. Zhu, "Coal and coalbed methane co-extraction technology based on the ground movement in the Yangquan coalfield, China," Energies, vol. 8, no. 7, pp. 6881-6897, 2015.

[26] F. Du and R. Gao, "Development patterns of fractured waterconducting zones in longwall mining of thick coal seams-A case study on safe mining under the Zhuozhang river," Energies, vol. 10, no. 11, p. 1856, 2017.

[27] M. Qian, X. Miao, J. Xu, and X. Mao, Study of Key Strata Theory in Ground Control, China University of Mining and Technology Press, Xuzhou, [in Chinese], 2003.

[28] J. L. Xu and M. G. Qian, "The effect of key strata activities on the movements of overlying strata and earth surface," Journal of China Coal Society, vol. 25, pp. 122-126, 2000.

[29] P. Li, X. Wang, W. Cao, D. Zhang, D. Qin, and H. Wang, "Influence of spatial relationships between key strata on the height of mining-induced fracture zone: a case study of thick coal seam mining," Energies, vol. 11, no. 1, p. 102, 2018.

[30] C. He, J. Xu, F. Wang, and F. Wang, "Movement boundary shape of overburden strata and its influencing factors," Energies, vol. 11, no. 4, p. 742, 2018.

[31] J. Ju and J. Xu, "Structural characteristics of key strata and strata behaviour of a fully mechanized longwall face with $7.0 \mathrm{~m}$ height chocks," International Journal of Rock Mechanics and Mining Sciences, vol. 58, pp. 46-54, 2013.

[32] R. Singh and T. N. Singh, "Investigation into the behavior of a support system and roof strata during sublevel caving of a thick coal seam," Geotechnical and Geological Engineering, vol. 17, no. 1, pp. 21-35, 1999.

[33] Z. Ma, P. Gong, J. Fan, M. Geng, and G. Zhang, "Coupling mechanism of roof and supporting wall in gob-side entry retaining in fully-mechanized mining with gangue backfilling," Mining Science and Technology (China), vol. 21, no. 6, pp. 829-833, 2011.

[34] X. Q. Long, "Calculation of Beam on Elastic Foundation," People's Education Press, Beijing, China, 1981. 